University of Nebraska - Lincoln

DigitalCommons@University of Nebraska - Lincoln

6-3-1998

\title{
Parameter Estimates for Direct, Maternal, and Grandmaternal Genetic Effects for Birth Weight and Weaning Weight in Hereford Cattle
}

\author{
J. Dodenhoff \\ University of Nebraska-Lincoln \\ L. Dale Van Vleck \\ University of Nebraska-Lincoln, dvan-vleck1@unl.edu \\ Stephen D. Kachman \\ University of Nebraska-Lincoln, steve.kachman@unl.edu \\ R. M. Koch \\ University of Nebraska-Lincoln, rkoch1@unl.edu
}

Follow this and additional works at: https://digitalcommons.unl.edu/animalscifacpub

Part of the Animal Sciences Commons

Dodenhoff, J.; Van Vleck, L. Dale; Kachman, Stephen D.; and Koch, R. M., "Parameter Estimates for Direct, Maternal, and Grandmaternal Genetic Effects for Birth Weight and Weaning Weight in Hereford Cattle" (1998). Faculty Papers and Publications in Animal Science. 276.

https://digitalcommons.unl.edu/animalscifacpub/276

This Article is brought to you for free and open access by the Animal Science Department at DigitalCommons@University of Nebraska - Lincoln. It has been accepted for inclusion in Faculty Papers and Publications in Animal Science by an authorized administrator of DigitalCommons@University of Nebraska - Lincoln. 


\title{
Parameter Estimates for Direct, Maternal, and Grandmaternal Genetic Effects for Birth Weight and Weaning Weight in Hereford Cattle ${ }^{1}$
}

\author{
J. Dodenhoff*,2,3, L. D. Van Vleck†, S. D. Kachman‡, and R. M. Koch* \\ *Department of Animal Science, University of Nebraska, Lincoln 68583; tRoman L. Hruska U.S. \\ Meat Animal Research Center, ARS, USDA, Lincoln, Nebraska 68583; and \\ ‡Department of Biometry, University of Nebraska, Lincoln 68583
}

\begin{abstract}
Birth and weaning weights adjusted for age of dam from four lines of Hereford cattle were analyzed to determine the relationships among grandmaternal, maternal, and direct genetic effects. Three lines were selected for 1 ) weaning weight (WWL), 2) yearling weight (YWL), and 3) an index of yearling weight and muscle score (IXL). The fourth line was an unselected control line (CTL). Numbers of observations ranged from 1,699 (CTL) to 2,811 (WWL), and number of animals in the pedigree file ranged from 2,266 to 3,192. Two animal models were used to obtain estimates by REML using an average information method. Model 1 included random direct and maternal genetic, permanent maternal environmental, and residual environmental effects, and fixed sex $x$ year effects. Model 2 additionally included random grandmaternal genetic and permanent grandmaternal environmental effects. For birth weight, Models 1 and 2 gave almost identical estimates for direct and maternal heritability, and for the fraction of variance that was due to maternal permanent environmental effects. Estimates for grandmaternal heritability could
\end{abstract}

be obtained only for IXL (.03) and CTL (.01). For weaning weight, estimates for direct heritability were similar from both models. Estimates for maternal heritability from Model 1 were .18, .20, .13, and .20, and corresponding estimates from Model 2 were .34, $.31, .13$, and .34 for WWL, YWL, IXL, and CTL, respectively. For $I X L$, estimates for variances that were due to grandmaternal genetic and grandmaternal permanent environmental variances could not be obtained and were set to zero. Grandmaternal heritability estimates for WWL, YWL, and CTL were .05, .09 , and .12. Estimates of correlations between direct and maternal genetic effects were $-.13,-.44,-.11$, and -.26 for $W W L, Y W L, I X L$, and CTL. Estimates of correlations between direct and grandmaternal genetic effects were .21, .83, and .55, and those between maternal and grandmaternal genetic effects were $-.99,-.84$, and -.76 for $W W L$, YWL, and CTL, respectively. These results indicate that grandmaternal effects may be important for weaning weight and that maternal heritability may be underestimated if grandmaternal effects are not included in the model.

Key Words: Beef Cattle, Growth, Genetic Parameters

@1998 American Society of Animal Science. All rights reserved.

J. Anim. Sci. 1998. 76:2521-2527

\section{Introduction}

Some traits of beef cattle have long been known to be affected by maternal effects (e.g., birth and weaning weights). For these traits, a random mater-

\footnotetext{
${ }^{1}$ Published as paper no. 12072, J ournal Ser., Nebraska Agric. Res. Div., Univ. of Nebraska, Lincoln 68583-0908. Support of the senior author by the German Research Foundation (DFG) is acknowledged.

${ }^{2}$ Current address: Department of Animal Science, Iowa State University, 109 Kildee Hall, Ames 50011-3150.

${ }^{3}$ To whom correspondence should be addressed: Department of Animal Science, lowa State University, 109 Kildee Hall, Ames 50011-3150; phone: 515/294-2240; fax: 515/294-3795.

Received November 3, 1997.

Accepted J une 3, 1998.
}

nal effect is recommended in models for genetic evaluation (BIF, 1996). Early on, rather complex models were found necessary to fully explain these traits. Koch and Clark (1955) presented a path diagram including the maternal granddam to illustrate the correlation between offspring and dam. Willham (1963) mentioned the possible influence of a grandmaternal effect. He suggested that the maternal effect of a dam may be affected by the maternal effect of the granddam. Falconer (1965) proposed the maternal effect as a linear function of a mother's phenotypic value influenced by all maternal ancestors. An example often given for a grandmaternal effect is the so-called fatty udder syndrome. A granddam with a superior maternal ability overfeeds her daughter, and thereby development of her daughter's udder tissue is inhibited such that the maternal ability of 
Table 1. Characteristics of the data

\begin{tabular}{lccccc}
\hline \hline Line & Records & Sires & Dams & Granddams & $\begin{array}{c}\text { Records without } \\
\text { granddam }\end{array}$ \\
\hline WWL & 2,811 & 92 & 791 & 466 & 66 \\
YWL & 2,706 & 95 & 783 & 465 & 65 \\
IXL & 2,752 & 95 & 766 & 446 & 70 \\
CTL & 1,699 & 91 & 631 & 436 & 14 \\
\hline
\end{tabular}
line.

the daughter is below average (Totusek et al., 1971). Among others, Willham (1972), Koch (1972), Baker (1980), and Cantet et al. (1988) were concerned that a negative influence of dams on their daughters' maternal ability, which is often discussed in terms of a negative dam-offspring correlation, may cause a negative bias in the covariance between direct and maternal effects. Animal models used to analyze maternally influenced traits typically include direct and maternal effects and the covariance between them, and a permanent environmental effect of the dam (e.g., Waldron et al., 1993, Robinson, 1996). Meyer (1992), who also used such a model, considered it to be suboptimal and pointed out that modeling of maternal effects in beef traits needed to be improved. Objectives of this study were to estimate grandmaternal effects for birth and weaning weights in Hereford cattle and to compare models including maternal effects with and without grandmaternal effects.

\section{Materials and Methods}

Data for this analysis were from a long-term selection experiment that began at Fort Robinson and concluded at USMARC, both in Nebraska (Koch et al., 1994). Starting with the formation of lines in 1960, three lines of Hereford cattle were selected for weaning weight ( $\mathbf{W} \mathbf{W L}$ ), yearling weight ( $\mathbf{Y W L}$ ), and an index of yearling weight and muscle score (IXXL). Another line was established in 1969 as an unselected control line (CTL). Records were from 1960 through 1985. N umbers of animals with records in the selected lines ranged from 2,702 to 2,811 . In CTL, there were 1,699 animals with records. Parents without records were added to the pedigree file so that the total number of animals was from 3,106 to 3,192 in the selected lines and 2,266 in the control line. Numbers of sires, dams, and granddams in each line are given in Table 1. Traits analyzed were birth weight and weaning weight, which was calculated as birth weight plus 200 times average daily gain to weaning. Records were standardized (Koch et al., 1994) and adjusted for age of dam. All animals had their birth and weaning weights recorded. Two single-trait animal models were used for this analysis. Model 1 was the same model as used by Koch et al. (1994):

$$
\mathbf{y}=\mathbf{X b}+\mathbf{Z}_{1} \mathbf{a}+\mathbf{Z}_{2} \mathbf{m}+\mathbf{W}_{1} \mathbf{p}+\mathbf{e}
$$

Model 2 was based on Model 1 and was extended to include grandmaternal effects:

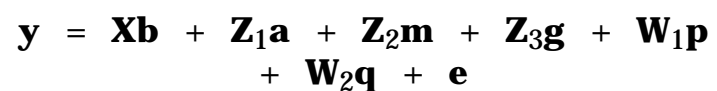

where $\mathbf{y}$ is an $\mathbf{N} \times 1$ vector of observations; $\mathbf{b}$ is the vector of fixed effects (sex $\times$ year); $\mathbf{a}, \mathbf{m}$, and $\mathbf{g}$ are vectors of breeding values for direct genetic, maternal genetic, and grandmaternal genetic effects; $\mathbf{p}$ and $\mathbf{q}$ are vectors of permanent maternal environmental and permanent grandmaternal environmental effects; $\mathbf{e}$ is the vector of random error effects; and $\mathbf{X}, \mathbf{Z}_{1}, \mathbf{Z}_{2}, \mathbf{Z}_{3}$, $\mathbf{W}_{1}$, and $\mathbf{W}_{2}$ are known incidence matrices that relate observations to their respective fixed and random effects. Matrices $\mathbf{Z}_{1}, \mathbf{Z}_{2}$, and $\mathbf{Z}_{3}$ were augmented for animals without records that were included in the relationship matrix.

For both models,

$$
\mathrm{E}[\mathbf{y}]=\mathbf{X b}
$$

The (co)variance structure of the random effects for Model 2 was $\mathbf{v}\left[\begin{array}{l}a \\ m \\ g \\ p \\ q \\ e\end{array}\right]=\mathbf{B}=$

$\left[\begin{array}{cccccc}\mathbf{A} \sigma_{\mathrm{a}}^{2} & \mathbf{A} \sigma_{\mathrm{am}} & \mathbf{A} \sigma_{\mathrm{ag}} & 0 & 0 & 0 \\ \mathbf{A} \sigma_{\mathrm{am}} & \mathbf{A} \sigma_{\mathrm{m}}^{2} & \mathbf{A} \sigma_{\mathrm{gm}} & 0 & 0 & 0 \\ \mathbf{A} \sigma_{\mathrm{ag}} & \mathbf{A} \sigma_{\mathrm{gm}} & \mathbf{A} \boldsymbol{\sigma}_{\mathrm{g}}^{2} & 0 & 0 & 0 \\ 0 & 0 & 0 & \mathbf{I}_{\mathrm{N}_{\mathrm{d}}} \boldsymbol{\sigma}_{\mathrm{p}}^{2} & 0 & 0 \\ 0 & 0 & 0 & 0 & \mathbf{I}_{\mathrm{N}_{\mathrm{g}}} \boldsymbol{\sigma}_{\mathrm{q}}^{2} & 0 \\ 0 & 0 & 0 & 0 & 0 & \mathrm{I}_{\mathrm{N}} \boldsymbol{\sigma}_{\mathrm{e}}^{2}\end{array}\right]$

where $\mathrm{N}_{\mathrm{d}}$ and $\mathrm{N}_{\mathrm{g}}$ are numbers of dams and granddams, respectively, and $\mathrm{N}$ is number of records; $\mathbf{A}$ is the numerator relationship matrix among animals in 
the pedigree file, and the I matrices are identity matrices. Let $\mathbf{Z}=\left[\mathbf{Z}_{\mathbf{1}}\left|\mathbf{Z}_{\mathbf{2}}\right| \mathbf{Z}_{\mathbf{3}}\right], \mathbf{W}=\left[\mathbf{W}_{\mathbf{1}} \mid \mathbf{W}_{\mathbf{2}}\right], \mathbf{u}^{\prime}=$ $\left[\mathbf{a}^{\prime}\left|\mathbf{m}^{\prime}\right| \mathbf{g}^{\prime}\right], \mathbf{c}^{\prime}=\left[\mathbf{p}^{\prime} \mid \mathbf{q}^{\prime}\right], \mathbf{V}(\mathbf{u})=\mathbf{G}, \mathbf{V}(\mathbf{c})=\mathbf{Q}$, and

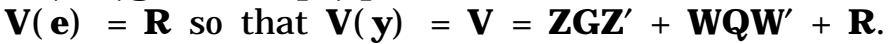

Model 2 required each animal with a record to have a granddam. Therefore, unique "dummy" granddams were used for records with the granddam unknown (Table 1). All dams were known and if unrelated as assumed at the initiation of the experiment, then the dummy granddams are unique but with a different identification than what they might have had originally.

\section{Estimation of Covariance Components}

Estimates by REML of (co)variances were obtained using an average information (Avl) algorithm as proposed by J ohnson and Thompson (1995). J ohnson and Thompson (1995) compared Avl REML with other methods and in their example found it to reach convergence five times faster than with a derivativefree algorithm and 15 times faster than with an expectation-maximization algorithm. As with the Newton-Raphson method and Fisher's method of scoring, this algorithm is a Newton method that uses first and second derivatives to find estimates of genetic parameters that maximize the likelihood function. The logarithm of the restricted maximum likelihood function is (e.g., Graser et al., 1987)

$L=-\frac{1}{2}\left[\right.$ constant $\left.+\ln |\mathbf{V}|+\ln \left|\mathbf{X}^{\prime} \mathbf{V}^{-1} \mathbf{X}\right|+\mathrm{y}^{\prime} \mathrm{Py}\right]$

where

$$
\mathbf{P}=\mathbf{V}^{-1}-\mathbf{V}^{-1} \mathbf{X}\left(\mathbf{X}^{\prime} \mathbf{V}^{-1} \mathbf{X}\right)^{-1} \mathbf{X}^{\prime} \mathbf{V}^{-1}
$$

The Newton-Raphson method uses the matrix of second derivatives (Hessian, $\mathbf{H}$ ) to maximize the likelihood function where, at the $m+1$ st iteration,

$$
\theta^{\mathrm{m}+1}=\theta^{\mathrm{m}}-\left(\mathbf{H}^{\mathrm{m}}\right)^{-1} \mathbf{k}^{\mathrm{m}}
$$

where $\theta$ is the vector of parameters and $\mathbf{k}$ is the vector of first derivatives of the likelihood function (the gradient or score function) for which the $i^{\text {th }}$ element can be written as

$$
\mathrm{k}_{\mathrm{i}}=\frac{\partial \mathbf{L}}{\partial \theta_{\mathrm{i}}}=-\frac{1}{2}\left[\operatorname{tr}\left(\mathbf{P} \frac{\partial \mathbf{V}}{\partial \theta_{\mathrm{i}}}\right)-\mathrm{y}^{\prime} \mathbf{P} \frac{\partial \mathbf{V}}{\partial \theta_{\mathrm{i}}} \mathbf{P y}\right]
$$

In Fisher's method of scoring (e.g., Searle et al., 1992) $\mathbf{H}$ is replaced by its expected value, $E[\mathbf{H}]$ :

$$
\theta^{\mathrm{m}+1}=\theta^{\mathrm{m}}-\left(\mathrm{E}\left[\mathbf{H}^{\mathrm{m}}\right]\right)^{-1} \mathbf{k}^{\mathrm{m}}
$$

where $-E[\mathbf{H}]$ is also called an information matrix. The matrices $\mathbf{H}$ and $E[\mathbf{H}]$ can be written (Searle et al., 1992) as

$$
\mathbf{H}=\frac{\partial^{2} \mathbf{L}}{\partial \theta_{\mathrm{i}} \partial \theta_{\mathrm{j}}}=\frac{1}{2} \operatorname{tr}\left(\mathbf{P} \frac{\partial \mathbf{V}}{\partial \theta_{\mathrm{i}}} \mathbf{P} \frac{\partial \mathbf{V}}{\partial \theta_{\mathrm{j}}}\right)-\mathbf{y}^{\prime} \mathbf{P} \frac{\partial \mathbf{V}}{\partial \theta_{\mathrm{i}}} \mathbf{P} \frac{\partial \mathbf{V}}{\partial \theta_{\mathrm{j}}} \mathbf{P y}
$$

and

$$
\mathrm{E}[\mathbf{H}]=\mathrm{E}\left[\frac{\partial^{2} \mathbf{L}}{\partial \theta_{\mathrm{i}} \partial \theta_{\mathrm{j}}}\right]=-\frac{1}{2} \operatorname{tr}\left(\mathbf{P} \frac{\partial \mathbf{V}}{\partial \theta_{\mathrm{i}}} \mathbf{P} \frac{\partial \mathbf{V}}{\partial \theta_{\mathrm{j}}}\right)
$$

Both the Hessian and its expected value include terms that are computationally demanding to calculate. J ohnson and Thompson (1995) noticed that the trace parts drop out if the two expressions are averaged:

$$
\text { Avl }=\frac{1}{2}(\mathbf{H}+\mathrm{E}[\mathbf{H}])=-\frac{1}{2} \mathrm{y}^{\prime} \mathbf{P} \frac{\partial \mathbf{V}}{\partial \theta_{\mathrm{i}}} \mathbf{P} \frac{\partial \mathbf{V}}{\partial \theta_{\mathrm{j}}} \mathbf{P y}
$$

Taking advantage of algebraic simplifications (J ohnson and Thompson, 1995) makes the average information matrix feasible to compute in some cases. A matrix $\mathbf{F}=\left\{\mathfrak{f}_{i}\right\}, \mathrm{i}=1, \ldots, \mathrm{r}$ of order $\mathrm{N} \times \mathrm{r}$ is defined, where $r$ is the number of elements in $\theta$, and the general vector $\mathbf{f}_{\mathrm{i}}$ is

$$
\mathbf{f}_{\mathrm{i}}=\frac{\partial \mathbf{v}}{\partial \theta_{\mathrm{i}}} \mathbf{P} \mathbf{y}=\mathbf{z} \frac{\partial \mathbf{G}}{\partial \theta_{\mathrm{i}}} \mathbf{G}^{-1} \hat{\mathbf{u}}+\mathbf{W}_{\partial \theta_{\mathrm{i}}}^{\partial \mathbf{Q}} \mathbf{Q}^{-1} \hat{\mathbf{c}}+\frac{\partial \mathbf{R}}{\partial \theta_{\mathrm{i}}} \mathbf{R}^{-1} \hat{\mathbf{e}}
$$

where $\mathbf{u}$ is the solution vector of the direct, maternal, and grandmaternal additive genetic effects, $\hat{\mathbf{c}}$ is the solution vector of the permanent maternal and grandmaternal environmental random effects, and $\hat{\mathbf{e}}$ is the solution vector of the residual effects. The average information matrix can be rewritten as

$$
\text { Avl }=-\mathbf{F}^{\prime} \mathbf{P F}=-\frac{1}{2}\left(\mathbf{F}^{\prime} \mathbf{R}^{-\mathbf{1}} \mathbf{F}-\left[\begin{array}{c}
\hat{\mathbf{b}}_{\mathrm{F}} \\
\hat{\mathbf{u}}_{\mathbf{F}} \\
\hat{\mathbf{C}}_{\mathrm{F}}
\end{array}\right]^{\prime}\left[\begin{array}{l}
\mathbf{X}^{\prime} \mathbf{R}^{-1} \mathbf{F} \\
\mathbf{Z}^{\prime} \mathbf{R}^{-1} \mathbf{F} \\
\mathbf{W}^{\prime} \mathbf{R}^{-1} \mathbf{F}
\end{array}\right]\right)
$$

To obtain $\hat{\mathbf{b}}_{\mathrm{F}}$, the solution vector for the fixed effects, $\hat{\mathbf{u}}_{F}$, and $\hat{\mathbf{c}}_{F}$ the MME are solved $r$ times with the $\mathbf{f}_{i}$ replacing $\mathbf{y}$, where MME are Henderson's mixed model equations (Henderson, 1975) corresponding to the mixed linear model [Model 2] and $\mathbf{V}(\mathrm{y})$.

Calculation of the first derivatives is shown for Model 2 where $\mathbf{k}$ has 10 elements. Six of the elements in $\mathbf{k}$ are first derivatives with respect to additive genetic (co)variances. Using expressions from J ohnson and Thompson (1995) and Madsen et al. (1994), they are calculated as

$$
\left[\begin{array}{ccc}
\mathbf{k}_{1} & 1 / 2 \mathbf{k}_{2}{ }^{1 / 2} \mathbf{k}_{3} \\
1 / 2 \mathbf{k}_{2} & \mathbf{k}_{4} & { }^{1 / 2} \mathbf{k}_{5} \\
1 / 2 \mathbf{k}_{3}{ }^{1 / 2} \mathbf{k}_{5} & \mathbf{k}_{6}
\end{array}\right]=\frac{1}{2}\left(\mathbf{G}_{0}^{-1}(\mathbf{T}+\mathbf{S}) \mathbf{G}_{0}^{-1}-\mathrm{N}_{\mathrm{a}} \mathbf{G}_{0}^{-1}\right)
$$

where $\mathrm{N}_{\mathrm{a}}$ is the number of animals in the pedigree file, and $\mathbf{G}_{0}$ is the (co)variance matrix of the additive genetic effects: 


$$
\begin{gathered}
\mathbf{G}_{0}=\left[\begin{array}{c}
\boldsymbol{\sigma}_{\mathrm{a}}^{2} \boldsymbol{\sigma}_{\mathrm{am}} \boldsymbol{\sigma}_{\mathrm{ag}} \\
\boldsymbol{\sigma}_{\mathrm{am}} \boldsymbol{\sigma}_{\mathrm{m}}^{2} \boldsymbol{\sigma}_{\mathrm{mg}} \\
\boldsymbol{\sigma}_{\mathrm{ag}} \boldsymbol{\sigma}_{\mathrm{mg}} \boldsymbol{\sigma}_{\mathrm{g}}^{2}
\end{array}\right], \\
\mathbf{T}=\left[\begin{array}{c}
\operatorname{tr}\left(\mathbf{A}^{-1} \mathbf{C}^{\mathrm{aa}}\right) \operatorname{tr}\left(\mathbf{A}^{-1} \mathbf{C}^{\mathrm{am}}\right) \operatorname{tr}\left(\mathbf{A}^{-1} \mathbf{C}^{\mathrm{ag}}\right) \\
\operatorname{tr}\left(\mathbf{A}^{-1} \mathbf{C}^{\mathrm{am}}\right) \operatorname{tr}\left(\mathbf{A}^{-1} \mathbf{C}^{\mathrm{mm}}\right) \operatorname{tr}\left(\mathbf{A}^{-1} \mathbf{C}^{\mathrm{mg}}\right) \\
\operatorname{tr}\left(\mathbf{A}^{-1} \mathbf{C}^{\mathrm{ag}}\right) \operatorname{tr}\left(\mathbf{A}^{-1} \mathbf{C}^{\mathrm{mg}}\right) \operatorname{tr}\left(\mathbf{A}^{-1} \mathbf{C}^{\mathrm{gg}}\right)
\end{array}\right]
\end{gathered}
$$

and

$$
\mathbf{S}=\left[\begin{array}{lll}
\hat{\mathbf{a}} \mathbf{A}^{-1} \hat{\mathbf{a}} & \hat{\mathbf{a}} \mathbf{A}^{-1} \hat{\mathbf{m}} & \hat{\mathbf{a}}^{\prime} \mathbf{A}^{-1} \hat{\mathbf{g}} \\
\hat{\mathbf{m}}^{\prime} \mathbf{A}^{-1} \hat{\mathbf{a}} & \hat{\mathbf{m}}^{\prime} \mathbf{A}^{-1} \hat{\mathbf{m}} & \hat{\mathbf{m}}^{\prime} \mathbf{A}^{-1} \hat{\mathbf{g}} \\
\hat{\mathbf{g}}^{\prime} \mathbf{A}^{-1} \hat{\mathbf{a}} & \hat{\mathbf{g}}^{\prime} \mathbf{A}^{-1} \hat{\mathbf{m}} & \hat{\mathbf{g}}^{\prime} \mathbf{A}^{-1} \hat{\mathbf{g}}
\end{array}\right]
$$

with $\hat{\mathbf{a}}, \hat{\mathbf{m}}$, and $\hat{\mathbf{g}}$ are the solution vectors for the direct, maternal, and grandmaternal additive genetic effects, and $\mathbf{C}^{\mathrm{aa}}, \mathbf{C}^{\mathrm{am}}, \mathbf{C}^{\mathrm{ag}}, \mathbf{C}^{\mathrm{mm}}$, and $\mathbf{C}^{\mathrm{gg}}$ are submatrices of the inverse of the coefficient matrix, $\mathbf{C}$. The FSPAK package (Perez-Enciso et al., 1992) was used to calculate this inverse. In FSPAK, an algorithm by Takahashi et al. (1973) is used to compute elements of a sparse matrix inverse corresponding to nonzero elements of the matrix.

The partial derivatives with respect to permanent environmental maternal $\left(\mathbf{k}_{7}\right)$ and permanent environmental grandmaternal variances $\left(\mathbf{k}_{9}\right)$ are calculated as

$$
\mathbf{k}_{7}=\frac{1}{2}\left[\frac{\operatorname{tr}\left(\mathbf{C}^{\mathrm{pp}}\right)+\hat{\mathbf{p}}^{\prime} \hat{\mathbf{p}}}{\sigma_{\mathrm{p}}^{4}}-\frac{\mathrm{N}_{\mathrm{d}}}{\sigma_{\mathrm{p}}^{2}}\right]
$$

and

$$
\mathbf{k}_{9}=\frac{1}{2}\left(\frac{\operatorname{tr}\left(\mathbf{C}^{\mathrm{qq}}\right)+\hat{\mathbf{q}}^{\prime} \hat{\mathbf{q}}}{\sigma_{\mathrm{q}}^{4}}-\frac{\mathrm{N}_{\mathrm{g}}}{\sigma_{\mathrm{q}}^{2}}\right)
$$

where $\hat{\mathbf{p}}$ and $\hat{\mathbf{q}}$ are the solution vectors of permanent environmental maternal and permanent environmental grandmaternal effects, and $\mathbf{C p p}$ and $\mathbf{C q q}$ are submatrices of the inverse of the coefficient matrix, $\mathbf{C}$. Because the covariance between the permanent environmental effects was assumed to be zero, $\mathbf{k}_{8}=0$.

Finally, the partial derivative with respect to the residual variance is

$$
\begin{aligned}
\mathbf{k}_{10}= & \frac{1}{2}\left[\frac{\hat{\mathbf{e}}^{\prime} \mathbf{e}}{\boldsymbol{\sigma}_{\mathrm{e}}^{4}}-\frac{N-\operatorname{tr}\left(\mathbf{M}^{\prime} \mathbf{R}^{-1} \mathbf{M} \mathbf{C}^{-}\right.}{\boldsymbol{\sigma}_{\mathrm{e}}^{2}}\right] \\
= & \frac{1}{2}\left[\frac{\hat{\mathbf{e}}^{\prime} \hat{\mathbf{e}}}{\boldsymbol{\sigma}_{\mathrm{e}}^{4}}-\frac{\mathrm{N}-\left(\mathrm{r}(\mathbf{X})+3 \mathrm{~N}_{\mathrm{a}}+\mathrm{N}_{\mathrm{d}}+\mathrm{N}_{\mathrm{g}}\right.}{\boldsymbol{\sigma}_{\mathrm{e}}^{2}}\right. \\
& -\frac{1}{\boldsymbol{\sigma}_{\mathrm{e}}^{2}}\left(\frac{\operatorname{tr}\left(\mathbf{A}^{-1} \mathbf{C}^{\mathrm{aa}}\right)}{\boldsymbol{\sigma}_{\mathrm{a}}^{2}}+\frac{\operatorname{tr}\left(\mathbf{A}^{-1} \mathbf{C}^{\mathrm{mm}}\right)}{\boldsymbol{\sigma}_{\mathrm{m}}^{2}}+\frac{\operatorname{tr}\left(\mathbf{A}^{-1} \mathbf{C}^{\mathrm{gg}}\right)}{\boldsymbol{\sigma}_{\mathrm{g}}^{2}}\right.
\end{aligned}
$$

$$
\begin{aligned}
& \left.+\frac{2 \operatorname{tr}\left(\mathbf{A}^{-1} \mathbf{C}^{\mathrm{am}}\right)}{\boldsymbol{\sigma}_{\mathrm{am}}}+\frac{2 \operatorname{tr}\left(\mathbf{A}^{-1} \mathbf{C}^{\mathrm{ag}}\right)}{\boldsymbol{\sigma}_{\mathrm{ag}}}+\frac{2 \operatorname{tr}\left(\mathbf{A}^{-1} \mathbf{C}^{\mathrm{mg}}\right)}{\boldsymbol{\sigma}_{\mathrm{mg}}}\right) \\
& \left.-\frac{1}{\boldsymbol{\sigma}_{\mathrm{e}}^{2}}\left(\frac{\operatorname{tr}\left(\mathbf{C}^{\mathrm{pp}}\right)}{\boldsymbol{\sigma}_{\mathrm{p}}^{2}}+\frac{\operatorname{tr}\left(\mathbf{C}^{\mathrm{qq}}\right)}{\boldsymbol{\sigma}_{\mathrm{q}}^{2}}\right)\right]
\end{aligned}
$$

where $\mathbf{M}=[\mathbf{X}|\mathbf{Z}| \mathbf{W}], \hat{\mathbf{e}}=\mathbf{y}-\mathbf{X} \hat{\mathbf{b}}-\mathbf{Z} \hat{\mathbf{u}}-\mathbf{W} \hat{\mathbf{c}}$, and $r(\mathbf{X})$ $=$ rank of $\mathbf{X}$.

The $m+1$ st iteration step using the average information matrix (Avl) is

$$
\theta^{\mathrm{m}+1}=\theta^{\mathrm{m}}+\left(\mathbf{A} \mathbf{v} \mathbf{l}^{\mathrm{m}}\right)^{-1} \mathbf{k}^{\mathrm{m}}
$$

The Euclidian norm of the gradient was used as the convergence criterion. Convergence was assumed to have been reached if the norm was less than $10^{-4}$.

\section{Standard Errors of Estimated Parameters}

The inverse of the negative average information matrix is an asymptotic dispersion matrix of the estimated parameters, $\mathrm{V}(\hat{\theta})=[-\mathbf{A v l}]^{-1}$. With a Taylor series expansion, variances of functions of random variables can be estimated (e.g., Stuart and Ord, 1994). Let $f(\hat{\theta})$ be a function of the estimated variance components (e.g., a heritability). Then a first-order Taylor series expansion to approach zero is

$$
f(\hat{\theta}) \approx f(\theta)+\left\{\frac{\partial f(\theta)}{\partial \theta^{\prime}}\right\}(\hat{\theta}-\theta)
$$

and the asymptotic variance of $f(\hat{\theta})$ can be estimated as

$$
\begin{aligned}
\mathrm{V}(\mathrm{f}(\hat{\theta})) & \approx \mathrm{V}\left(\mathrm{f}(\theta)+\left\{\frac{\partial \mathrm{f}(\theta)}{\partial \theta^{\prime}}\right\}(\hat{\theta}-\theta)\right) \\
& \approx\left\{\frac{\partial f(\theta)}{\partial \theta^{\prime}}\right\} \mathrm{V}(\hat{\theta})\left\{\frac{\partial \mathrm{f}(\theta)}{\partial \theta}\right\}
\end{aligned}
$$

For example, the vector of partial derivatives of the direct heritability in Model 2 is

$\frac{\partial h^{2}}{\partial \theta^{\prime}}=$

$\left[\frac{\mathrm{h}^{2}-\mathrm{h}^{4}}{\sigma_{\mathrm{a}}^{2}}-\frac{\mathrm{h}^{4}}{\sigma_{\mathrm{a}}^{2}}-\frac{\mathrm{h}^{4}}{\sigma_{\mathrm{a}}^{2}}-\frac{\mathrm{h}^{4}}{\sigma_{\mathrm{a}}^{2}}-\frac{\mathrm{h}^{4}}{\sigma_{\mathrm{a}}^{2}}-\frac{\mathrm{h}^{4}}{\sigma_{\mathrm{a}}^{2}}-\frac{\mathrm{h}^{4}}{\sigma_{\mathrm{a}}^{2}} 0-\frac{\mathrm{h}^{4}}{\sigma_{\mathrm{a}}^{2}}-\frac{\mathrm{h}^{4}}{\sigma_{\mathrm{a}}^{2}}\right]$

and the standard error of the estimate of $h^{2}$ is calculated as

$$
\operatorname{SE}\left(h^{2}\right) \approx \sqrt{\left\{\frac{\partial h^{2}}{\partial \theta^{\prime}}\right\}(-\mathbf{A v l})^{-1}\left\{\frac{\partial h^{2}}{\partial \theta}\right\}}
$$


Table 2. Parameter estimates ${ }^{\mathrm{a}}$ and standard errors (in parentheses) for birth weight

\begin{tabular}{|c|c|c|c|c|c|c|c|c|c|c|c|c|c|c|c|c|c|c|}
\hline \multirow[b]{2}{*}{ Line $^{b}$} & \multicolumn{7}{|c|}{ Model 1} & \multicolumn{11}{|c|}{ Model 2} \\
\hline & $-2 \log L$ & $h^{2}$ & $\mathrm{~m}^{2}$ & $r_{a m}$ & $p^{2}$ & $e^{2}$ & $\sigma_{\mathrm{P}}$ & $-2 \log \mathrm{L}$ & $h^{2}$ & $\mathrm{~m}^{2}$ & $g^{2}$ & $r_{a m}$ & $r_{a g}$ & $r_{\mathrm{mg}}$ & $p^{2}$ & $q^{2}$ & $e^{2}$ & $\sigma_{\mathrm{P}}$ \\
\hline$W W L^{c}$ & 2,096.97 & $\begin{array}{l}.45 \\
(.068)\end{array}$ & $\begin{array}{c}.10 \\
(.033)\end{array}$ & $\begin{array}{c}.15 \\
(.182)\end{array}$ & $\begin{array}{l}.01 \\
(.020)\end{array}$ & $\begin{array}{l}.40 \\
(.048)\end{array}$ & .98 & $2,096.97$ & $\begin{array}{l}.45 \\
(.068)\end{array}$ & $\begin{array}{c}.10 \\
(.033)\end{array}$ & - & $\begin{array}{c}.15 \\
(.182)\end{array}$ & - & - & $\begin{array}{c}.01 \\
(.020)\end{array}$ & - & $\begin{array}{l}.40 \\
(.048)\end{array}$ & .98 \\
\hline YWL & $1,967.73$ & $\begin{array}{l}.47 \\
(.076)\end{array}$ & $\begin{array}{l}.09 \\
(.037)\end{array}$ & $\begin{array}{l}-.07 \\
(.193)\end{array}$ & $\begin{array}{l}.04 \\
(.023)\end{array}$ & $\begin{array}{l}.41 \\
(.055)\end{array}$ & .96 & $1,967.65$ & $\begin{array}{l}.47 \\
(.076)\end{array}$ & $\begin{array}{c}.09 \\
(.037)\end{array}$ & - & $\begin{array}{l}-.07 \\
(.194)\end{array}$ & - & - & $\begin{array}{l}.04 \\
(.030)\end{array}$ & $\begin{array}{l}.01 \\
(.020)\end{array}$ & $\begin{array}{l}.41 \\
(.054)\end{array}$ & .96 \\
\hline$I X L$ & $2,130.62$ & $\begin{array}{l}.38 \\
(.066)\end{array}$ & $\begin{array}{c}.14 \\
(.041)\end{array}$ & $\begin{array}{l}.15 \\
(.174)\end{array}$ & $\begin{array}{c}.02 \\
(.023)\end{array}$ & $\begin{array}{c}.43 \\
(.047)\end{array}$ & .99 & $2,127.68$ & $\begin{array}{c}.39 \\
(.068)\end{array}$ & $\begin{array}{c}.13 \\
(.053)\end{array}$ & $\begin{array}{l}.03 \\
(.025)\end{array}$ & $\begin{array}{c}.20 \\
(.182)\end{array}$ & $\begin{array}{l}-.30 \\
(.286)\end{array}$ & $\begin{array}{l}-.01 \\
(.416)\end{array}$ & $\begin{array}{c}.01 \\
(.033)\end{array}$ & - & $\begin{array}{l}.43 \\
(.048)\end{array}$ & .99 \\
\hline CTL & $1,373.66$ & $\begin{array}{c}.39 \\
(.071)\end{array}$ & $\begin{array}{l}.11 \\
(.035)\end{array}$ & $\begin{array}{l}.29 \\
(.241)\end{array}$ & $\begin{array}{l}- \\
-\end{array}$ & $\begin{array}{l}.45 \\
(.054)\end{array}$ & 1.00 & $1,372.68$ & $\begin{array}{c}.38 \\
(.073)\end{array}$ & $\begin{array}{c}.09 \\
(.037)\end{array}$ & $\begin{array}{c}.01 \\
(.019)\end{array}$ & $\begin{array}{l}.25 \\
(.256)\end{array}$ & $\begin{array}{c}.26 \\
(.645)\end{array}$ & $\begin{array}{c}.39 \\
(.758)\end{array}$ & $\begin{array}{l}- \\
-\end{array}$ & - & $\begin{array}{c}.45 \\
(.054)\end{array}$ & 1.00 \\
\hline
\end{tabular}

$\mathrm{a}^{2}=$ direct heritability, $\mathrm{m}^{2}=$ maternal heritability, $\mathrm{g}^{2}=$ grandmaternal heritability, $\mathrm{r}_{\text {am }}=$ genetic correlation between direct and maternal effects, $r_{a g}=$ genetic correlation between direct and grandmaternal effects, $r_{m g}=$ genetic correlation between maternal and grandmaternal effects, $\mathrm{p}^{2}=$ fraction of variance due to maternal permanent environmental effects, $\mathrm{q}^{2}=$ fraction of variance due to grandmaternal permanent environmental effects, $\mathrm{e}^{2}=$ fraction of variance due to temporary environmental effects, $\sigma_{\mathrm{P}}=$ phenotypic standard deviation.

bWWL = weaning wt, YWL = yearling wt, IXL = index of yearling wt and muscle score, CTL = control line.

cModels are identical because parameters for grandmaternal effects failed to converge in the parameter space.

A likelihood ratio test was used to compare the models (Dobson, 1990). Even though Model 2 had potentially five additional (co)variance components compared with Model 1 , the difference between the $-2 \mathrm{~L}$ values was assumed to be $\chi^{2}$ distributed with four degrees of freedom because the covariance between the maternal and grandmaternal permanent environmental effects was assumed to be 0 . The critical values for significance are $9.49(P<.05)$ and $13.28(P<.01)$.

\section{Results and Discussion}

\section{Birth Weight}

Parameter estimates for birth weight from Models 1 and 2 for each of the four lines are shown in Table 2. Estimates for WWL and IXL from Model 1 agree well with those obtained by Koch et al. (1994), who analyzed data from the same experiment but from a shorter time span (1960-1982) so that the number of animals in each of the lines was less. Additive genetic heritability $\left(\mathrm{h}^{2}\right)$ was greater for YWL (.47 vs .43) and for CTL (.39 vs .34) than in Koch et al. (1994), and the correlation between direct and maternal effects $\left(r_{\mathrm{am}}\right)$ was smaller in CTL (.29 vs .46). For $C T L$, the fraction of variance that was due to permanent maternal environmental effects $\left(p^{2}\right)$ could not be estimated for either Model 1 or 2 (i.e., during the iteration process, the estimate tended to become negative and was therefore set to zero). Meyer (1992) and Waldron et al. (1993) used the same animal model as Model 1 to analyze Hereford data from Australia and New Zealand, respectively. Even though estimates of Meyer (1992) were similar to those in Table 2, Waldron et al. (1993) found a lower direct heritability (.24) and a larger correlation between direct and maternal effects (.37). Results from earlier studies, mostly obtained from sire-maternal grandsire models, often showed negative correlations between direct and maternal effects (for review, see Meyer (1992).

In none of the lines could all of the effects additionally fitted in Model 2 be estimated. For WWL, neither the fraction that was due to grandmaternal genetic variance $\left(\mathrm{g}^{2}\right)$ nor the fraction of variance due to permanent grandmaternal environmental effects $\left(q^{2}\right)$ could be estimated so that Model 2 gave the same results as Model 1 . When the grandmaternal genetic variance tended to become negative during iteration, it was set to a very small positive value $\left(10^{-8}\right)$ in order to keep $\mathbf{G}_{0}$ positive definite while the appropriate covariances were set to 0 . A small $q^{2}(.01)$ was estimated for YWL, but, compared with Model 1, the other estimates were not affected. For IXL, an estimate of $\mathrm{g}^{2}$ could be obtained (.03) but not an estimate of $q^{2}$. The estimate of the correlation between the direct and the grandmaternal effects $\left(r_{a g}\right)$ was negative $(-.30)$. The correlation $\left(r_{\mathrm{mg}}\right)$ between maternal and grandmaternal effects was slightly negative $(-.01)$. Compared with Model $1, r_{a m}$ increased from .15 to .20; $\mathrm{h}^{2}, \mathrm{~m}^{2}$, and $\mathrm{p}^{2}$ changed only slightly; and the fraction of variance due to residual effects $\left(e^{2}\right)$ did not change at all. A small $g^{2}$ was also estimated for CTL. The $r_{\text {ag }}$ and $r_{\mathrm{mg}}$ were positive, .26 and .39 , respectively. The estimate of $r_{a m}$ decreased from .29 in Model 1 to .25 in Model 2. In this line, neither $p^{2}$ nor $q^{2}$ could be estimated. Likelihood ratio tests showed that the $-2 \mathrm{~L}$ values for Model 2 were not significantly less than those for Model 1 .

Results indicate that grandmaternal effects do not play an important role in birth weight. This result agrees with Koch (1972), who concluded that maternal ability of cows was not affected by their dam's maternal ability, whereas Cantet et al. (1988) obtained estimates of -.15 for the path between maternal phenotypes of dam and daughter. Koch 
Table 3. Parameter estimates ${ }^{\mathrm{a}}$ and standard errors (in parentheses) for weaning weight

\begin{tabular}{|c|c|c|c|c|c|c|c|c|c|c|c|c|c|c|c|c|c|c|}
\hline \multirow[b]{2}{*}{ Line $^{b}$} & \multicolumn{7}{|c|}{ Model 1} & \multicolumn{11}{|c|}{ Model 2} \\
\hline & $-2 \log \mathrm{L}$ & $h^{2}$ & $\mathrm{~m}^{2}$ & $r_{a m}$ & $p^{2}$ & $e^{2}$ & $\sigma_{\mathrm{P}}$ & $-2 \log L$ & $h^{2}$ & $\mathrm{~m}^{2}$ & $g^{2}$ & $r_{a m}$ & $r_{a g}$ & $r_{\mathrm{mg}}$ & $p^{2}$ & $q^{2}$ & $e^{2}$ & $\sigma_{\mathrm{P}}$ \\
\hline WWL & $2,202.96$ & $\begin{array}{l}.18 \\
(.051)\end{array}$ & $\begin{array}{c}.18 \\
(.052)\end{array}$ & $\begin{array}{l}-.22 \\
(.169)\end{array}$ & $\begin{array}{c}.24 \\
(.039)\end{array}$ & $\begin{array}{l}.44 \\
(.038)\end{array}$ & 1.00 & $2,190.96^{c}$ & $\begin{array}{l}.18 \\
(.049)\end{array}$ & $\begin{array}{c}.34 \\
(.102)\end{array}$ & $\begin{array}{c}.04 \\
(.042)\end{array}$ & $\begin{array}{l}-.13 \\
(.151)\end{array}$ & $\begin{array}{l}.20 \\
(.362)\end{array}$ & $\begin{array}{l}-.99 \\
(.309)\end{array}$ & $\begin{array}{l}.07 \\
(.068)\end{array}$ & $\begin{array}{l}.07 \\
(.037)\end{array}$ & $\begin{array}{l}.43 \\
(.038)\end{array}$ & 1.01 \\
\hline YWL & $1,957.85$ & $\begin{array}{l}.13 \\
(.042)\end{array}$ & $\begin{array}{l}.20 \\
(.057)\end{array}$ & $\begin{array}{l}-.35 \\
(.171)\end{array}$ & $\begin{array}{l}.29 \\
(.041)\end{array}$ & $\begin{array}{l}.44 \\
(.033)\end{array}$ & .98 & $1,937.49^{d}$ & $\begin{array}{l}.14 \\
(.039)\end{array}$ & $\begin{array}{l}.31 \\
(.094)\end{array}$ & $\begin{array}{l}.09 \\
(.051)\end{array}$ & $\begin{array}{l}-.44 \\
(.148)\end{array}$ & $\begin{array}{l}.83 \\
(.286)\end{array}$ & $\begin{array}{l}-.84 \\
(.145)\end{array}$ & $\begin{array}{l}.16 \\
(.062)\end{array}$ & $\begin{array}{l}.03 \\
(.042)\end{array}$ & $\begin{array}{l}.41 \\
(.035)\end{array}$ & 1.01 \\
\hline$I X L^{e}$ & $2,346.76$ & $\begin{array}{l}.16 \\
(.045)\end{array}$ & $\begin{array}{l}.13 \\
(.051)\end{array}$ & $\begin{array}{l}-.11 \\
(.224)\end{array}$ & $\begin{array}{l}.29 \\
(.039)\end{array}$ & $\begin{array}{l}.44 \\
(.035)\end{array}$ & 1.04 & $2,346.76$ & $\begin{array}{l}.16 \\
(.045)\end{array}$ & $\begin{array}{l}.13 \\
(.051)\end{array}$ & - & $\begin{array}{l}-.11 \\
(.224)\end{array}$ & $\begin{array}{l}- \\
-\end{array}$ & - & $\begin{array}{l}.29 \\
(.039)\end{array}$ & $\frac{-}{-}$ & $\begin{array}{l}.44 \\
(.035)\end{array}$ & 1.04 \\
\hline CTL & $1,273.72$ & $\begin{array}{l}.10 \\
(.042)\end{array}$ & $\begin{array}{l}.20 \\
(.070)\end{array}$ & $\begin{array}{l}-.25 \\
(.241)\end{array}$ & $\begin{array}{l}.28 \\
(.053)\end{array}$ & $\begin{array}{l}.45 \\
(.038)\end{array}$ & .98 & 1,266.61 & $\begin{array}{l}.10 \\
(.039)\end{array}$ & $\begin{array}{l}.34 \\
(.124)\end{array}$ & $\begin{array}{l}.12 \\
(.068)\end{array}$ & $\begin{array}{l}-.26 \\
(.221)\end{array}$ & $\begin{array}{l}.55 \\
(.400)\end{array}$ & $\begin{array}{l}-.76 \\
(.148)\end{array}$ & $\begin{array}{l}.15 \\
(.084)\end{array}$ & - & $\begin{array}{l}.44 \\
(.039)\end{array}$ & 1.00 \\
\hline
\end{tabular}

$\mathrm{a}^{2}=$ direct heritability, $\mathrm{m}^{2}=$ maternal heritability, $\mathrm{g}^{2}=$ grandmaternal heritability, $\mathrm{r}_{\mathrm{am}}=$ genetic correlation between direct and maternal effects, $r_{a g}=$ genetic correlation between direct and grandmaternal effects, $r_{m g}=$ genetic correlation between maternal and grandmaternal effects, $p^{2}=$ fraction of variance due to maternal permanent environmental effects, $q^{2}=$ fraction of variance due to grandmaternal permanent environmental effects, $\mathrm{e}^{2}=$ fraction of variance due to temporary environmental effects, $\sigma_{\mathrm{P}}=$ phenotypic standard deviation.

bWWL = weaning wt, YWL = yearling wt, IXL = index of yearling wt and muscle score, $\mathrm{CTL}=$ control line.

${ }^{C}$ Function value smaller $(P<.05)$ than the function value for Model 1.

${ }^{d}$ Function value smaller $(P<.01)$ than the function value for Model 1 .

e Models are identical because parameters for grandmaternal effects failed to converge in the parameter space.

(1972) and Cantet et al. (1988) used Falconer's (1965) concept of a geometric series accounting for all female ancestors.

\section{Weaning Weight}

Shown in Table 3 are the parameter estimates for weaning weight for each of the four lines. With Model 1 , estimates of $h^{2}, m^{2}, r_{a m}$, and $p^{2}$ for $Y W L, I X L$, and CTL were similar to those in Koch et al. (1994). For WWL, $\mathrm{h}^{2}$ and $\mathrm{m}^{2}$ were greater (.18 and .18 vs .13 and .14 ), and $p^{2}$ was less (.24 vs .29). Estimates of $m^{2}$ were of the same magnitude as $h^{2}$ for WWL and IXL, which is similar to results of Meyer (1992) and Waldron et al. (1993). For YWL and CTL, $\mathrm{m}^{2}$ was larger than $\mathrm{h}^{2}$ in agreement with Skaar (1985) and Koch et al. (1994) for Herefords.

With Model 2, small to moderate estimates for the variance of grandmaternal effects were estimated for WWL (.04), YWL (.09), and CTL (.12), but for IXL no estimate of $g^{2}$ could be obtained. For CTL, $g^{2}$ was greater than $h^{2}\left(.12\right.$ vs .10). Small estimates of $q^{2}$ were found for WWL (.07) and YWL (.03). Direct heritability estimates did not change from Model 1 to Model 2, but maternal heritability was considerably affected. The estimate of $\mathrm{m}^{2}$ increased for WWL from .18 to .34 , for $Y W L$ from .20 to .31, and for CTL from .20 to .34 , which indicated that the contribution of maternal effects may be underestimated with Model 1 . Correlation between direct and maternal genetic effects decreased (WWL), increased (YWL), and did not change (CTL). Correlations between direct and grandmaternal effects were moderate (.20 for WWL) to high (.83 for YWL). Large negative correlations were found between maternal and grandmaternal effects. Estimates of $p^{2}$ decreased by about the same amount that $\mathrm{m}^{2}$ increased. For $\mathrm{WWL}, \mathrm{p}^{2}$ was of the same magnitude as $q^{2}(.07)$. The decrease in $p^{2}$ was similar for the three lines regardless of whether an estimate of $\mathrm{q}^{2}$ could be obtained. Likelihood ratio tests showed that Model 2 was a significantly better fit to the data than Model 1 for WWL $(P<.05)$ and $Y W L$ $(P<.01)$. For $I X L$, the likelihood values are identical because the grandmaternal effects became negative and were set to zero, which made Models 1 and 2 identical.

The large negative estimates for $r_{m g}$ suggest that the negative influence of a dam's maternal ability on the maternal ability of her daughter may be even stronger than suspected in the past. Koch (1972) suggested a dam-offspring regression coefficient of -.10 to -.20 for gain from birth to weaning, and Cantet et al. (1988) found a similar value of -.25 for weaning weight. Analyses for other traits (not presented) gave results for gain from birth to weaning similar to weaning weight, and grandmaternal effects did not seem to be important for postweaning gain, final weight, muscle score, and an index of yearling weight and muscle score.

\section{Implications}

Results of this study suggest that grandmaternal effects may be important for weaning weight. Estimates of variance that is due to grandmaternal effects are moderate, and correlations with direct and maternal genetic effects are large. Maternal heritability seems to be considerably underestimated if grandmaternal effects are not included in the model but exist. Further research might be necessary to determine whether considerable reranking of animals occurs by using models that include grandmaternal effects. 


\section{Literature Cited}

Baker, R. L. 1980. The role of maternal effects on the efficiency of selection in beef cattle: A review. Proc. N. Z. Soc. Anim. Prod. 40:285-303.

BIF. 1996. Guidelines for Uniform Beef Improvement Programs (7th Ed.). Beef Improvement Federation, Colby, KS.

Cantet, R.J .C., D. D. Kress, D. C. Anderson, D. E. Doornbos, P. J . Burfening, and R. L. Blackwell. 1988. Direct and maternal variances and covariances and maternal phenotypic effects on preweaning growth of beef cattle. J. Anim. Sci. 66:648-660.

Dobson, A. J . 1990. An Introduction to Generalized Linear Models. Chapman and Hall, New York.

Falconer, D. S. 1965. Maternal effects and selection response. In: Genetics Today. Proc. XI Int. Cong. of Genetics. Vol. 3, The Hague, The Netherlands. p 763.

Graser, H.-U., S. P. Smith, and B. Tier. 1987. A derivative-free approach for estimating variance components in animal models by restricted maximum likelihood. J . Anim. Sci. 64:1362-1370.

Henderson, C. R. 1975. Best linear estimation and prediction under a selection model. Biometrics 31:423-447.

J ohnson, D. L., and R. Thompson. 1995. Restricted maximum likelihood estimation of variance components for univariate animal models using sparse matrix techniques and average information. J. Dairy Sci. 78:449-456.

Koch, R. M. 1972. The role of maternal effects in animal breeding: VI. Maternal effects in beef cattle. J . Anim. Sci. 35:1316-1323.

Koch, R. M., and R. T. Clark. 1955. Genetic and environmental relationships among economic characters in beef cattle. III. Evaluating maternal environment. J . Anim. Sci. 14:979-996.

Koch, R. M., L. V. Cundiff, and K. E. Gregory. 1994. Cumulative selection and genetic change for weaning or yearling weight or for yearling weight plus muscle score in Hereford cattle. J. Anim. Sci. 72:864-885.

Madsen, P., J . J ensen, and R. Thompson. 1994. Estimation of (co)variance components by REML in multivariate mixed linear models using average of observed and expected information. In: Proc. 5th World Congr. Genet. Appl. Livest. Prod. Guelph. 22:19-22.

Meyer, K. 1992. Variance components due to direct and maternal effects for growth traits of Australian beef cattle. Livest. Prod. Sci. 31:179-203.

Perez-Enciso, M., I. Misztal, and M. A. Elzo. 1994. FSPAK-An interface for public domain sparse matrix subroutines. Proc. 5th World Congress Gen. Appl. Livest. Prod. Guel ph, 22:77-78.

Robinson, D. L. 1996. Estimation and interpretation of direct and maternal genetic parameters for the weights of Australian Angus cattle. Livest. Prod. Sci. 45:1-11.

Searle, S. R., G. Casella, and C. E. McCulloch. 1992. Variance Components. J ohn Wiley and Sons, New York.

Skaar, B. R. 1985. Direct genetic and maternal variance and covariance estimates from Angus and Hereford field data. Ph.D. dissertation. I owa State University, Ames.

Stuart, A., and J. K. Ord. 1994. Kendall's Advanced Theory of Statistics. Volume 1: Distribution Theory (6th Ed.). Halsted Press, New York.

Takahashi, K., J. Fagan, and M. S. Chin. 1973. Formation of a sparse bus impedance matrix and its application to short circuit study. In: Proc. 8th Inst. PICA Conf. Minneapolis, MN. p 63.

Totusek, R., O. F. Stephens, J. R. Kropp, S. W. Holloway, J. W. Knosi, and J. V. Whiteman. 1971. Milk production of range cows. Okla. Agric. Ext. Sta. Misc. Pub. 85.

Waldron, D. F., C. A. Morris, R. L. Baker, and D. L. J ohnson. 1993. Maternal effects for growth traits in beef cattle. Livest. Prod. Sci. 34:57-69.

Willham, R. L. 1963. The covariance between relatives for characters composed of components contributed by related individuals. Biometrics 19:18-27.

Willham, R. L. 1972. The role of maternal effects in animal breeding: III. Biometrical aspects of maternal effects in animals. J. Anim. Sci. 35:1288-1293. 